BULLETIN of the International Association of ENGINEERING GEOLOGY I'Association Internationale de GEOLOGIE DE L'INGENIEUR $^{\circ} 17$

\section{ON THE LABORATORY DETERMINATION OF SHEAR STRENGTH}

BOŽINOVIČ D., Faculty of Mining and Geology, Belgrade,
Yugoslavia

The value of resistance which can be introduced to oppose shearing along existing or potential sliding surface is one of the most important factors for the prognostication of terrain stability. Of special importance is the shear strength along the existing discontinuities which are generally numerous in old, temporarily quiescent landslides found in weathered cohesive rock masses.

In order to improve the technique of shear strength tests on small standard samples, the team working in the Laboratory for Soil Mechanics of the Faculty of Mining and Geology of Belgrade makes increasingly frequent use of a special triaxial test by which the necessary parameters can be obtained from a single sample of soil. The test is especially advantageous in the case of non-homogeneous rock masses.

An increase in axial stress brings about an increase in lateral pressure as a function of rigidity of the sample, i.e. of its vertical and horizontal deformations.

By regulating the horizontal deformation of the sample with a view to the problem to be solved, it is possible to find out the main stress ratio, the deformation ratio, and to determine the parameters of Coulomb's shearing strength equation of the sample under a given set of conditions.

The method of loading used in this test is being further developed by Paprica, and experienced member of the laboratory staff, and will be fully reported in Madrid next year.

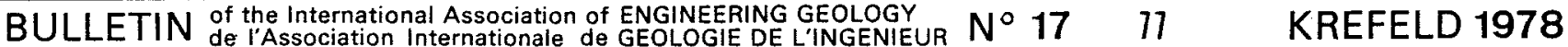

\section{PRUŠKKA L., Prague, Czechoslovakia}

Soil is an example of granular material consisting of individual grains and of water and air in pores between the grains. The shear strength of soils is determined by the frictional forces arising during slip at the contacts between the soil particles. For practical purposes the maximum resistance to shear on any plane is given by the modified NewtonCoulomb expression

$$
\tau_{\mathrm{f}}=(\sigma \mp \mathrm{u}) \cdot \tan \phi^{\prime}+\mathrm{c}^{\prime}
$$

where $\sigma$ is the total pressure normal to the plane of shear,

$u$ is the pore pressure,

$\phi^{\prime}$ is the effective angle of internal friction and

$c^{\prime}$ is the effective apparent cohesion.

The term $(\sigma \mp u)$ denotes the effective pressure and leads to the expression

$$
\sigma=\left(\sigma^{\prime} \pm u\right)
$$

showing, that both the effective pressure and the pore pressure are independent. In the case of the constant total pressure, the pore pressure influences the shear resistance. The greater the pore pressure the smaller the shear resistance.
In most engineering problems relating to stability, the magnitude of the total normal stress on a potential slip surface may be estimated with reasonable accuracy from considerations of statics.

On the other hand, the magnitude and the changes in pore pressure are influenced by several factors. One of these factors, which is very important, is dilatancy, that is, changes in volume of soil due to shear at constant pressure along the slip surface. Dilatancy is the source of changes in pore pressure and of effective pressures as well. The changes in effective pressures cause changes in the resistance to shear. If the volume of the soil along the slip surface increases, the pore pressure decreases and the shearing resistance increases. The movement of the sliding mass is slowing down to a stop. The sliding goes on after dissipation of the decrement of the pore pressure or on a new slip surface created in the unstable mass outside the zone with the decreased pore pressure. The dilatancy accompanied by the decrease in pore pressure leads to the creation of two or more slip surfaces on which sliding alternates.

The influence of changes in pore pressure on the stability of slopes is important in deep excavations particularly in saturated clays. The excavation means the unloading of slopes and the decrease of pore pressure often up to negative values. The following consolidation (negative) implies the increase of pore pressure and the decrease of shear strength. Therefore the stability of slopes is greatest immediately after excavation and decreases with the time of consolidation.

\section{\begin{tabular}{|lllll}
\hline BULLETIN of the International Association of ENGINEERING GEOLOGY & $N^{\circ} 17$ & $17-78$ & KREFELD 1978 \\
\hline
\end{tabular}}

FEDA J., Institute of Theoretical and Applied Mechanics of the Czechoslovak Academy of Sciences, Prague, Czechoslovakia

During this Symposium many examples of the successful application of the engineering geological methods were presented to explain different modes of slope movements. The contribution to Theme 2 by Nemčok and Mahr richly illustrated by slides were especially instructive in this respect.

Nevertheless it seems that the classical engineering geological methods based on stratigraphy, geology (esp. tectonic) history and morphology are approaching the point of diminishing return. There seems to be a need for their rejuvenation by new ideas. Such an opportunity provides, to my opinion, more intensive application of geomechanics to the engineering geology. It enables us to take into account the quantitative point of view of slope movements. Such an approach will doubtlessly facilitate the choice of the most probable alternative explanation for these causes and development of an engineering geological process.

This may be exemplified by the slope movements of the block type. Kamenov et al. assume that the soft rock underlying the moving blocks is deformed plastically without distinct sliding surfaces (typical of contractant behaviour). Košták sugests, on the contrary, the origin of sliding surfaces under such circumstances as was also clearly demonstrated by his film record presented at this session. The initiation of slip surfaces is rather indicative of dilatant behaviour. Both these types of behaviour are closely connected with the structure (and texture) of the investigated soil and rock, which deserves therefore to be subjected to a close scrutiny especially when exposed to the effect of time.

The effect of time on the mechanical behaviour of Cretaceous claystones from Strahov (Prague) was studied in the laboratory in connection with the above mentioned investigation by Košták of the mechanism of block movements in the Bohemian Cretaceous formations. A torsional shear box apparatus was used.

It has been revealed that the rate of distortional and volumetric creep does not drop uniformly with time. It may increase either with the increase of stress to the level of the long-term shearing resistance (shear to normal stress ratio $0.59,0.66$ and 0.83 in Fig. 1) or through a distinct time interval at a constant stress level (e.g. $\tau / \sigma_{\mathrm{B}}=0.45$ in Fig. 1). In the course of the deformation process the plastic component of the displacement gradually increases (Fig. 2), indicating the growing intensity of structural changes. The stabilized ratio of the reversible and total displacement (see Fig. 2 at $\tau / \sigma_{n}=0.4$ to 0.5 ) seems to indicate 